Journal of Animal and Veterinary Advances 11 (2): 181-185, 2012

ISSN: $1680-5593$

(C) Medwell Journals, 2012

\title{
Establishment of a Multiplex PCR and an Investigation of Co-Infection Rate of WSSV and IHHNV in Penaeid vannamei in Northern of Jiangsu
}

\author{
${ }^{1}$ Yi-Bing Chen, ${ }^{3}$ Jun-Fang Zhou, ${ }^{4} \mathrm{Xi}-\mathrm{He}$ Wan and ${ }^{2}$ Song Gao \\ ${ }^{1}$ College of Animal Science and Technology, \\ ${ }^{2}$ College of Veterinary Medicine, Yangzhou University, 25009 Yangzhou, China \\ ${ }^{3}$ Jiangsu Institute of Oceanography, Marine Fisheries, 226007 Nantong, China \\ ${ }^{4}$ East China Sea Fisheries Research Institute, Chinese Academy of Fishery Sciences, \\ 200090 Shanghai, China
}

\begin{abstract}
Based on the conservative regions in genome of WSSV and IHHNV, two specific primer sets, respectively for the two viruses were designed and constructed. A multiplex PCR for co-detection of the two viruses with a specificity of (IHHNV, TSV, YHV, Vibrio Parahaemolyticus, etc.) and sensitivity of $1 \times 10^{3}$ template copy numbers was subsequent established after serially optimization. WSSV and IHHNV with different template concentrations could be detected simultaneously. By the multiplex PCR method, 265 diseased shrimp samples and 169 healthy shrimp samples collected from the farms in the Northern area of Jiangsu province was investigated for WSSV and IHHNV co-infection rate in pond-cultured $P$. vannamei. The results show that the infection rate of WSSV was quite high ( $45 \sim 54 \%$ ) whereas that of IHHNV was very low (6.9 13.7\%). The result also indicated that there were $7 \sim 10 \%$ of diseased shrimp and $0 \sim 6.7 \%$ of healthy shrimp were co-infected with the two viruses indicated that co-infection of the two viruses was more popular in diseased shrimp than the healthy.
\end{abstract}

Key words: White spot syndrome virus, infectious hypodermal and hematopoietic necrosis virus, multiplex PCR, co-infection, templates, China

\section{INTRODUCTION}

Penaeid vannamei are cultured in the most area of worldwide because of its high production and salt tolerance. In recent years with the breakthrough of freshwater cultivation technology, $P$. vannamei become the dominant species of shrimp cultured in China and the annual production of which is occupied $>50 \%$ of shrimp cultivated in China and played an important role in the export business. However with the continuous expansion of cultural area and the increasing intensivism, shrimp diseases, especially shrimp viral disease is explosive and epizootic in many aquaculture farms. The aquaculture disease prediction system in some areas shows that White Spot Syndrome (WSS) and Infectious Hypodermal and Hematopoietic Necrosis disease (IHHN) are the most important two viral diseases restraining rapid development of $P$. vannamei aquaculture industry in China.

White Spot Syndrome Virus (WSSV) and Infectious Hypodermal and Hematopoietic Necrosis Virus (IHHNV) were responsible to WSS and IHHN in shrimp, respectively. WSSV has high pathogenic characteristics and high mortality rate. The mortality rate of shrimp will be up to $100 \%$ within 3-10 days post infection (Lightner, 1996). The virus has a broad host tropism and almost all of the crustaceans could be infected with which or become the virus host (Lo et al., 1996). WSSV infection rate of shrimp cultured in China has been maintained at high level (Zhou et al., 2011) and WSS is listed by the World Organization for Animal Health (OIE) as first class disease. IHHNV can infect both wild and cultured shrimp. $P$. stylirostri has high morbidity and mortality (Lightner et al., 1983). Although, P. vannamei has the certain resistance of IHHNV, chronic runt-deformity syndrome, RDS caused by the virus will lead to shrimp slow growth and significant economic losses (Kalagayan et al., 1991). Therefore, IHHN is listed by OIE as second class disease. Currently, virus infection was found in shrimp aquaculture in various regions of China (Yang et al., 2007). Previous studies showed that virus can cause arthropod repeated infection characteristics. One kind of the animal can be prevalently infected by two or two more viruses (Chayaburakul et al., 2004; Raia et al., 2009). As both WSSV and IHHNV can infect $P$. vannamei and transmit prevalently (Lo et al., 1996; Yang et al.,

Corresponding Author: Yi-Bing Chen, College of Animal Science and Technology, Yangzhou University, 25009 Yangzhou, China 
2007). The repeated infection of both two viruses will make the significant impact of economic benefit of $P$. vannamei aquaculture certainly. Aalso there is no obvious disease outbreak symptoms after IHHNV-infected and very difficult to make clinical diagnosis. Therefore, finding a rapid and sensitive molecular biology detection method is very necessary to indicate two virus infection, especially co-infection timely. Yangzhou, Taizhou, Nantong, Yancheng, Liany-ungang and other regions in Northern of Jiangsu have rich fresh water resource and wide cultured water. $P$. vannamei is the main cultured species in these regions.

In order to grasp the transmission and co-infection of both WSSV and IHHIV in P. vannmei cultures this study establish a multiplex PCR detection method of WSSV and IHHNV by adopting molecular biology measures and make investigation of virus co-infection rate to $P$. vannamei cultures in Northern of Jiangsu by adopting this method.

\section{MATERIALS AND METHODS}

Experimental materials: During the period of 2009 and 2010, 265 diseased $P$. vannamei samples and 169 non-diseased healthy shrimp samples were collected from Yang zhou, Taizhou, Nantong, Yancheng, Lianyungang and other regions of aquaculture farms. All samples were stored with ice in the incubator and would be taken to the laboratory within $4 \mathrm{~h}$. Samples sources are shown in Table 1.

WSSV positive comparison virus strain was supplied by Jiangsu Institute of Oceanography, Marine Fisheries and Marine Biotechnology Laboratory. IHHNV, TSV, YHV and Vibrio Parahaemolyticus positive comparison were collected from Ocean University of China.

Primer design and synthesis: Based on the conservative regions in WSSV (AF440570) and IHHNV genome (AF218226), a pair of specific primers was designed by adopting the software prime 5 to amplify 1320 and $356 \mathrm{bp}$ products, respectively. WSSV primers were P1 (5'-TAATCACGGTTGCCAAACAA-3'), P2 (5'-CACGGTCAACATGTCTCCTG-3'); IHHNV primers were F1 (5'-ATCGGTGCACTACTCGA-3'), F2 (5'-TCGTACTGGCTGTTCATC-3'). Primers were synthesized by Shanghai Sheng Gong Bioengineering Co., Ltd.

Table 1: $P$. vannamei WSSV and IHHNV infection samples composition in Northern of Jiangsu during y ear, 2009 and 2010

\begin{tabular}{|c|c|c|c|c|c|}
\hline Regions & Yangzhou & Taizhou & Nantong & Yancheng & Lianyungang \\
\hline $\begin{array}{l}\text { Diseased shrimp } \\
\text { (Qty) }\end{array}$ & 51 & 48 & 60 & 43 & 63 \\
\hline $\begin{array}{l}\text { Healthy shrimp } \\
\text { (Qty) }\end{array}$ & 30 & 33 & 39 & 32 & 35 \\
\hline
\end{tabular}

Template DNA preparation: A total of $25-50 \mathrm{mg}$ diseased $P$. vannamei cephalothorax were homogenized in the centrifuge tube and mixed equally with $1 \mathrm{~mL}$ split solution liquid $\left(100 \mathrm{mmol} \mathrm{L}^{-1} \mathrm{naC} ; 10 \mathrm{mmol} \mathrm{L}^{-1}\right.$ Tris- $\mathrm{HCl} \mathrm{pH}$ value 8.0, 25 mmol L ${ }^{-1}$ LEDTA, $\mathrm{pH}$ value $8.0,2 \% \mathrm{SDS}, 0.5 \%$ N-laurylsarcosine; $0.5 \mathrm{mg} \mathrm{mL}^{-1}$ proteinase $\mathrm{K}$ ) at $65^{\circ} \mathrm{C}$ water for $1 \mathrm{~h}$, adding $5 \mathrm{M} \mathrm{NaCl}$ to make $\mathrm{NaCl}$ final concentration to be $0.7 \mathrm{M}$, slowly adding $10 \%$ volume of $\mathrm{CTAB} / \mathrm{NaCl}$, mixed equally at $65^{\circ} \mathrm{C}$ water for $10 \mathrm{~min}$, adding equal volume of 24:1 chloroform/isoamyl alcohol and extracted after mixed equally. Water free ethanol precipitated DNA, 70\% ethanol washed. After dried, dissolved in $0.1 \times \mathrm{TE}$ solution preserved at $-20^{\circ} \mathrm{C}$.

PCR optimization amplification condition: Optimized under the condition of recommended DNA template concentration by applied the method recommended by Taq DNA polymerase reagents. The cycle times, $\mathrm{MgCl}_{2}$ concentration, primer concentration, Taq enzyme concentration and other parameters were optimized respectively based on the optimized annealing temperature. Annealing temperatures were 50, 53, 56, 58, 60 and $63^{\circ} \mathrm{C}$, respectively. Compared with falling PCR program, falling $\mathrm{PCR}$ program was $95^{\circ} \mathrm{C}$ denatured for $4 \mathrm{~min}$, then denatured $94^{\circ} \mathrm{C}$ for $30 \mathrm{sec}$, annealed for $30 \mathrm{sec}$, $72^{\circ} \mathrm{C}$ for $1 \mathrm{~min}$ each annealing temperature was interval $2^{\circ} \mathrm{C}$ as 2 cycles. The rest cycles were completed at last $52^{\circ} \mathrm{C}$. The total cycle times were set $20,25,30,35$ and 40 times, $72^{\circ} \mathrm{C}$ extended for $10 \mathrm{~min}$. $\mathrm{MgCL}_{2}$ concentration was set $0.5,1.0,1.5,2.0$ and $3.0 \mu \mathrm{L}$. Primer concentration was set $0.1,0.2,0.3,0.4,0.5,0.6$ and $0.7 \mu \mathrm{L}$. Taq DNA polymerase concentration were set $0.02,0.03,0.04,0.05$, $0.06,0.08$ and $0.10 \mathrm{U} \mu \mathrm{L}^{-1}$. The total volume was $25 \mu \mathrm{L}$ which contained $1.0 \times \mathrm{PCR}$ reaction buffer, $200 \mu \mathrm{M}$ dNTP, DNA sample $1 \mu \mathrm{L}$ and deionized water. Amplification product was detected by electrophoresis in $1.5 \%$ agarose gel.

Double PCR specificity, sensitivity and interference detection: Utilizing the total ingested DNA as the template and applying the above WSSV and IHHNV primers $(\mathrm{P} 1 / \mathrm{P} 2, \mathrm{~F} 1 / \mathrm{F} 2)$, PCR was detected on the positive comparison strain by adopting multiplex PCR detection method established in this study.

Positive template was amplified by 10 times serial dilutions $\left(1 \times 10^{10}\right.$ copies $\mu \mathrm{L}^{-1} \sim 1 \times 10$ copies $\left.\mu \mathrm{L}^{-1}\right)$ to determine the minimum detection limit. Multiplex PCR detection was carried out on the positive samples, mixed-positive samples and negative comparison samples simultaneously. Repeat detection after $96 \mathrm{~h}$ and stored in the template DNA at $-20^{\circ} \mathrm{C}$ to verify stability. Combined WSSV and IHHNV standard samples according to the different relative concentrations $\left(1 \times 10^{8} ; 1 \times 10^{4}, 1 \times 10^{5}\right.$; $1 \times 10^{5}, 1 \times 10^{4}$ and $1 \times 10^{8}$ copies $\mu \mathrm{L}^{-1}$ ), multiplex PCR and 
single PCR were detected, respectively and analyzed if the detection between WSSV and IHHNV were existed the mutual interfere phenomena.

WSSV and IHHNV double infection rate survey: The gills of healthy $P$. vanname $i$ and $25-50 \mathrm{mg}$ cephalothorax of diseased $P$. vannamei were taken, respectively. Sample's total DNA were ingested based on the method above and amplify according to the multiplex PCR method. And set up the healthy shrimp group for comparison simultaneously. Amplification products were detected by electrophoresis in $1.5 \%$ agarose gel and the results were observed in the gel imaging system and photographed.

\section{RESULTS AND DISCUSSION}

\section{WSSV and IHHNV double PCR detection method:} Optimum condition was adopted falling PCR, $\mathrm{MgCl}_{2}$ concentration $1.50 \mu \mathrm{L}$, WSSV primer concentration $0.5 \mu \mathrm{L}$, IHHNV primer concentration $0.3 \mu \mathrm{L}$, Taq DNA polymerase $0.04 \mu \mathrm{L}, 1.0 \times \mathrm{PCR}$ reaction buffer, $200 \mu \mathrm{M}$ dNTP, DNA samples $1 \mu \mathrm{L}$, deionized water to compensate the volume. Falling PCR program was at $95^{\circ} \mathrm{C}$ denatured for $4 \mathrm{~min}$ then denature $94^{\circ} \mathrm{C}$ for $30 \mathrm{sec}$, annealing $62-54^{\circ} \mathrm{C}$ for $30 \mathrm{sec}$, $72^{\circ} \mathrm{C}$ for $1 \mathrm{~min}$ each annealing temperature is interval $2^{\circ} \mathrm{C}$ as 2 cycle times. The rest cycles were completed at last $52^{\circ} \mathrm{C}$. The total cycle times were set 35 times. About $72^{\circ} \mathrm{C}$ extended for $10 \mathrm{~min}$. Amplification product was detected by electrophoresis in 1.5\% agarose gel and the results were observed in the gel imaging system and photographed. Results are shown in Fig. 1.

Multiplex PCR had good specificity. The obvious bands of PCR reaction to WSSV positive strain, IHHNV positive strain, WSSV and IHHNV mixed strain and healthy shrimp muscle negative comparison strain were clearly found on the electrophoresis figure and conformed to the expected bands size shown in Fig. 1.

Sensitivity detection result showed that two clear bands were appeared when the positive template was diluted to $1 \times 10^{3}$ while there was no purpose amplified band when diluted to $1 \times 10^{2}$. Details are shown in Fig. 2 . Multiplex PCR method had the strong anti-interference characteristics. Different relative concen-tration virus samples had no obvious anti-interference characteristics to the results. The results are shown in Fig. 2.

WSSV and IHHNV co-infection rate: In early stage of disease outbreak, the body of shrimp is become soft, alone, stay aside or slow swimming in the water, reduction in food consumption or even without eating and is appeared empty stomach. Body, liver, pancreas and even intestine are become red. Liver and pancreas are swelling

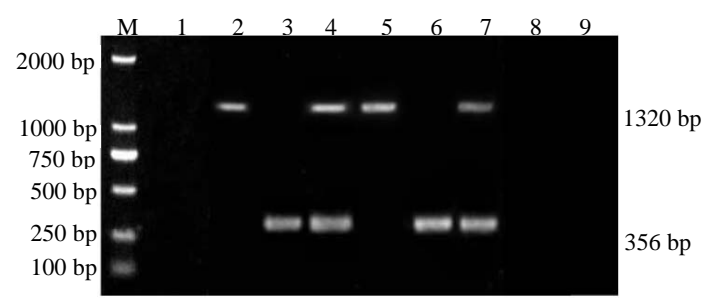

Fig. 1: Results of WSSV and IHHNV Double PCR detection method; 1: Negative comparison; 2: WSSV positive comparison; 3: IHHNV positive comparison; 4: WSSV and IHHNV mixed positive comparison; 5: WSSV positive sample; 6: IHHNV positive sample; 7: WSSV and IHHNV positive sample; 8: Healthy shrimp meat sample; 9: Healthy shrimp gills sample

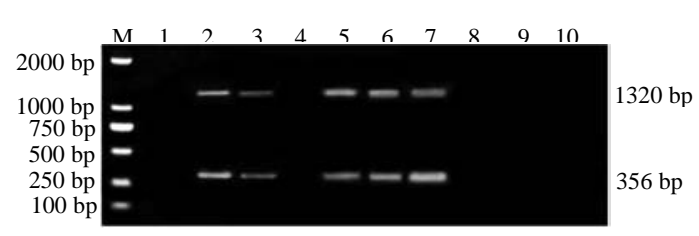

Fig. 2: Results of sensitivity and specificity of WSSV and IHHNV Double PCR detection method; 1: Negative comparison; 2: Template $1 \times 10^{4}$ virus copy concentration sample; 3 : Template $1 \times 10^{3}$ virus copy concentration sample; 4: Template $1 \times 10^{2}$ virus copy concentration sample; 5: Template $1 \times 10^{8}$ virus copy of WSSV: Template $1 \times 10^{4}$ virus copy of IHHNV; 6: Template $1 \times 10^{5}$ virus copy of WSSV: Template $1 \times 10^{5}$ virus copy of IHHNV; 7 : Template $1 \times 10^{4}$ virus copy of WSSV: Template $1 \times 10^{8}$ virus copy of IHHNV; 8 : TSV positive sample; 9: YHV positive sample; 10: Arc germ positive sample

and so on. Head, cuirass and abdominal segment shells are easy to be peeled. There are unscraped white spots inside some shrimp shells. Table 2 shows that WSSV infection rate of diseased shrimp group was higher. The infection rate in five regions was between 30 and $60 \%$. IHHNV infection rate was lower than WSSV. However, it was attained about $10 \%$. Virus total positive rate was between 45 and $60 \%$. Thereinto, two virus co-infection rates were 9.8, 8.3, 10, 7.0 and 9.5\% in Yangzhou, Taizhou, Nantong, Yancheng and Lianyungang cities. However, WSSV virus was detected from the healthy shrimp group in five regions. IHHNV virus was detected in four regions and failed to detect in one region. The total positive rate of both viruses was between 30 and $40 \%$. Thereinto, virus co-infection rates were $6.7,0,5.1,6.3$ and $2.9 \%$, failed to detect IHHNV positive infection separately. After 
J.Anim.Vet.Adv., 11 (2): 181-185, 2012

Table 2: P. vannamei WSSV and IHHNV infection rate in Northern of Jiangsu during year, 2009 and 2010

\begin{tabular}{|c|c|c|c|c|c|}
\hline Regions & Yangzhou & Taizhou & Nantong & Yancheng & Lanyungang \\
\hline \multicolumn{6}{|l|}{ Diseased shrimp group } \\
\hline Shrimp sample (Qty) & 51.0 & 48.0 & 60.0 & 43.0 & 63.0 \\
\hline Single WSSV positive shrimp (Qty) & 18.0 & 18.0 & 25.0 & 17.0 & 28.0 \\
\hline Single IHHNV positive shrimp (Qty) & 2.0 & 1.0 & 2.0 & 0.0 & 1.0 \\
\hline Double infection shrimp (Qty) & 5.0 & 4.0 & 6.0 & 3.0 & 6.0 \\
\hline Total virus positive rate (\%) & 49.0 & 48.0 & 55.0 & 46.5 & 55.6 \\
\hline Doulbe infection rate $(\%)$ & 9.8 & 8.3 & 10.0 & 7.0 & 9.5 \\
\hline \multicolumn{6}{|l|}{ Healthy non-diseased shrimp group } \\
\hline Shrimp sample (Qty) & 30.0 & 33.0 & 39.0 & 32.0 & 35.0 \\
\hline Single WSSV positive shrimp (Qty) & 9.0 & 10.0 & 12.0 & 10.0 & 11.0 \\
\hline Single IHHNV positive shrimp (Qty) & 0.0 & 0.0 & 0.0 & 0.0 & 0.0 \\
\hline Double infection shrimp (Qty) & 2.0 & 0.0 & 2.0 & 2.0 & 1.0 \\
\hline Total virus positive rate (\%) & 36.7 & 30.3 & 35.9 & 37.5 & 34.3 \\
\hline Double infection rate $(\%)$ & 6.7 & 0.0 & 5.1 & 6.3 & 2.9 \\
\hline
\end{tabular}

undergoing the devastating attack caused by explosive WSSV in the 90 s of the last century, the aquaculture enterprises in China have increased the shrimp disease prevention consciousness to the unparalleled extent. Although shrimp immune system disfigurement causes the lack of prevention drug with the continuous improvement of disease diagnosis (Kim et al., 1998; Yang et al., 2005), SPF seed cultivation and variety of immune intensifier and the water quality regulator adopted, shrimp, especially $P$. vannamei aquaculture has been walked out the bottom vale in a short time and achieved the rapid growth of shrimp production in the world since, 2000. With the expansion of farm area and highly focus on disease prevention. It does not seem that the current challenge to the shrimp aquaculture is caused by the declined production because of diseases while is caused by low prices and declined profits because of the fierce market competition. In fact, according to the aquaculture diseases detection prediction, the most important disease which threatens to China's shrimp aquaculture is still the viral disease currently. The economic losses caused by shrimp virus disease are up to $50 \%$ and more than the other diseases combination caused. Cultured enterprises should focus on disease prevention and control in order to minimize production costs increase productivity and profitability so that they can stand firmly in the fierce international market competition. Therefore, prevention and control of shrimp viral diseases are still the crux of shrimp aquaculture sustainable development.

WSSV and IHHNV are the common pathogen of P. vannamei (Yang et al., 2005; Sankar et al., 2011) which are widespread in Asia and the Pacific region. The survey results show that WSSV and IHHNV single and co-infection rate of healthy $P$. vannmei in Northern of Jiangsu are quite high which is consistent with the related domestic reviews (Yang et al., 2007). In fact, virus co-infection phenomenon in the crustacean host is very widespread (Chayaburakul et al., 2004; Raia et al., 2009). The study shows that (Tang et al., 2003; Melena et al., 2006) when IHHNV infect shrimp potentially, it does not prevent other viruses such as WSSV repeated infection.
But IHHNV can reduce obviously disease risk caused by WSSV through the antagonism function of the viruses so that, the balance can be achieved and latent together through the interaction between two virus and host shrimp. Finally cause multiple virus persistent infection shrimp status. Obviously because virus repeated infection can cause pathogenic factors complicated, clinic symptom and pathological analysis and so on have a big captivation characteristics. It is easy to cause diagnostic error, delay and seriously affect disease prevention timely and accurately. Secondly, P. vannamei has quite good tolerance and Disease Symptom (RDS) is not obvious. Its easy to make farmers neglect. Finally because repeated infection is potential and disease is not outbreak (Tang et al., 2003) when the secondary virus WSSV infection volume is quite high caused by the virus mutual restrict. It increases the risk of disease prevention virtually. Because of many species of infected virus and quite big infection volume, once cultured conditions have changed suddenly, diseased will be outbreak quickly. Practicable prevention time and control measures are unavailable and economy losses will be very severe (Zhou et al., 2011; Li et al., 2008). The above shows that at the moment of very popular virus repeated infection, its essential to detect cultured shrimp important virus infection in the body at any time by sensitive and specific molecular biology methods (e.g., PCR). In accordance with the status of shrimp virus repeated infection this study established WSSV and IHHNV multiplex PCR detection method. Samples detection results show that the method has the specificity, sensitive and strong anti-interference characteristics and is suitable to show WSSV and IHHNV single and co-infection in the shrimp body simultaneously and accurately from minor shrimp samples. Therefore, this method can not only save related detection reagent and materials greatly but also win the valued preparation time for disease prediction alarm by shortening greatly double virus diagnostic procedure. This study investigated results indicate that WSSV and IHHNV single and co-infection rate are quite high in the body of cultured $P$. vannamei in Northern of Jiangsu and indicate that WSSV and IHHNV are the main infected virus of cultured 
$P$. vannamei in this region. While the high infection rate of two pathogens in the body of healthy shrimp can warn the potential risk of disease outbreak. Therefore in the progress of cultivation, on one hand, local cultured enterprises should strengthen management and strictly prevent important stimulated factors influence (Zhou et al., 2011; Li et al., 2008) and adopt immunity strengthened reagent to increase shrimp self-immunity power. On the other hand, due to the lack of shrimp particular prevention and treatment drugs, WSSV and IHHNV multiplex PCR technique should be adopted to detect virus infection status at any time and carry out preventive measures timely.

\section{CONCLUSION}

A multiplex PCR for co-detection of the two viruses with a specificity of (IHHNV, TSV, YHV, Vibrio Parahaemolyticus, etc.) and sensitivity of $1 \times 10^{3}$ template copy numbers was established after serially optimization to investigate for WSSV and IHHNV co-infection rate in pond-cultured $P$. vannamei in this study. This method can not only save related detection reagent and materials greatly but also win the valued preparation time for disease prediction alarm by shortening greatly double virus diagnostic procedure. The investigated results indicate that WSSV and IHHNV single and co-infection rate are quite high in the body of cultured $P$. vanname $i$ in Northern of Jiangsu and indicate that WSSV and IHHNV are the main infected virus of cultured $P$. vannamei in this region.

\section{ACKNOWLEDGEMENT}

This research was supported by grants from National Nature Science Foundation of Jiangsu province (BK201 0269).

\section{REFERENCES}

Chayaburakul, K., G. Nash, P. Pratanpipat, S. Sriurairatana and B. Withyachumnarnkul, 2004. Multiple pathogens found in growth-retarded black tiger shrimp Penaeus monodon cultivated in Thailand. Dis. Aquat Org., 60: 89-96.

Kalagayan, H., D. Godin, R. Kanna, G. Hagino, J. Sweeney, J. Wyban and J. Brock, 1991. IHHN Virus as an Etiological Factor in Runt-Deformity Syndrome (RDS) of Juvenile Penaeus vannamei Cultured in Hawaii. J. World Aquacult. Soc., 22: 235-243.

Kim, C.K., P.K. Kim, S.G. Sohn, D.S. Sim and M.A. Park et al., 1998. Development of a polymerase chain reaction (PCR) procedure for the detection of baculovirus associated with white spot syndrome (WSBV) in penaeid shrimp. J. Fish Dis., 21: 11-17.
Li, Y.W., Y.C. Cao, Z.J. Li, Y.Y. Yang and G.L. Wen, 2008. Review of the relationship between White Spot Syndrome (WSS) and ambient factors in prawn-culture waters. J. Adv. Mar. Sci., 26: 532-537, (In Chinese).

Lightner, D.V., 1996. A Handbook of Pathology and Diagnostic Procedures for Diseases of Cultured Penaeid Shrimp. World Aquaculture Society, Baton Rouge, LA., Pages: 304.

Lightner, D.V., R.M. Redman, T.A. Bell and J.A. Brock, 1983. Detection of IHHN virus in Penaeus stylirostris and $\mathrm{P}$. vannamei imported into Hawaii. J. World Mariculture Soc., 14: 212-225.

Lo, C.F., C.H. HO, S.E. Peng, C.H. Chen and H.C. Hsu et al., 1996. White spot syndrome baculovirus (WSBV) detected in cultured and captured shrimp, crabs and other arthropods. Dis. Aquat Org., 27: 215-225.

Melena, J., B. Bayot, I. Betancourt, Y. Amano and F. Panchana et al, 2006. Pre-exposure to infectious hypodermal and haematopoietic necrosis virus or to inactivated white spot syndrome virus (WSSV) confers protection against WSSV in Penaeus vannamei (Boone) post-larvae. J. Fish Dis., 29: $589-600$.

Raia, P., B. Pradeepa, M.P. Safeenaa, I. Karunasagara and I. Karunasagar, 2009. Simultaneous presence of infectious hypodermal and hematopoietic necrosis virus (IHHNV) and Type A virus-related sequence in Penaeus monodon from India. Aquaculture, 295: 168-174.

Sankar, G., K. Ramamoorthy, K. Sakkaravarthi and S. Vanitha, 2011. Prevalence of shrimp viral pathogen (WSSV) in marine ecosystem. Aquacult. Aquarium Conserv Legislation, 4: 40-45.

Tang, K.F.J., S.V. Durand, B.L. White, R.M. Redman, L.L. Mohney and D.V. Lightner, 2003. Induced resistance to white spot syndrome virus infection in Penaeus stylirostris through pre-infection with infectious hypodermal and hematopoietic necrosis virus - a preliminary study. Aquaculture, 216: 19-29.

Yang, B., X.L. Song, J. Huang and Z.W. Lei, 2005. Epidemiology and diagnosis of disease by infectious hypodermal and hematopoietic necrosis virus (IHHNV)-A review. J. Fishery Sci. China, 12: 519-524.

Yang, B., X.L. Song, J. Huang, C.Y. Shi and L. Liu, 2007. Evidence of existence of infectious hypodermal and hematopoietic necrosis virus in Penaeid shrimp cultured in China. Vet. Microbiol., 120: 63-70.

Zhou, J.F., X.L. Yang, X. Wan, L.L. HU, S. zhou and W.H. Fang, 2011. Investigation of the effect of aquaculture density on the infection and outbreak of white spot disease (WSD) in litopenaeus vannamei. J. Jilin Agric. Univ., 33: 79-83. 